\title{
THE IMPACT OF INCREASED STABILITY AND EFFICIENCY THROUGH AUTOMATIC CONTROL SYSTEM FOR A STEAM POWER PLANT
}

\author{
Ion Marian Popescu
}

Assistant professor, Ph.D, Faculty of Automation, Computers and Electronics, Department of Automation and Electronics, University of Craiova, Craiova, Romania, pmarian@automation.ucv.ro

Postdoctoral Researcher at University of Craiova

\begin{abstract}
This paper shows necessity for a new dynamic evolution of a energy goup in the context of, in the energy system, the wind and photovoltaic energy have priority. The actual automatic control systems, already implemented, allow analysis of more than 5,000 measuring points in real time, but also very consistent evolutionary history. In this context it is proposed and analysis solution, based on closed loop modeling, which can lead to knowledge of this complex process. Knowing with a high degree of accuracy of this process can lead to redesigning the control algorithms in the direction of increasing the stability and efficiency.
\end{abstract}

Key words: closed-loop modeling, energy system, green energy

1. Aspects of the competition between "green energy" and "energy produced from fossil fuels"

As it is expected, "the green electrical energy", represented by wind and photovoltaic energy has priority in any energy system. Because electrical energy can not be stored, electric power consumption instantly be permanently sustained. Storing coal and obtaining coal-fired electric power allows its use when other sources are exhausted: for hydropower drought, periods when the wind does not blow in wind power, photovoltaic energy for cloudy periods.

In this context, because nuclear energy production can not vary in time, it remains the only solution that thermoelectric energy production from coal, to compensate the electricity consumption as shown in Fig.1. [6] This highly dynamic of operation of a thermal power group is currently possible, due to actual distributed automation systems that are implemented.
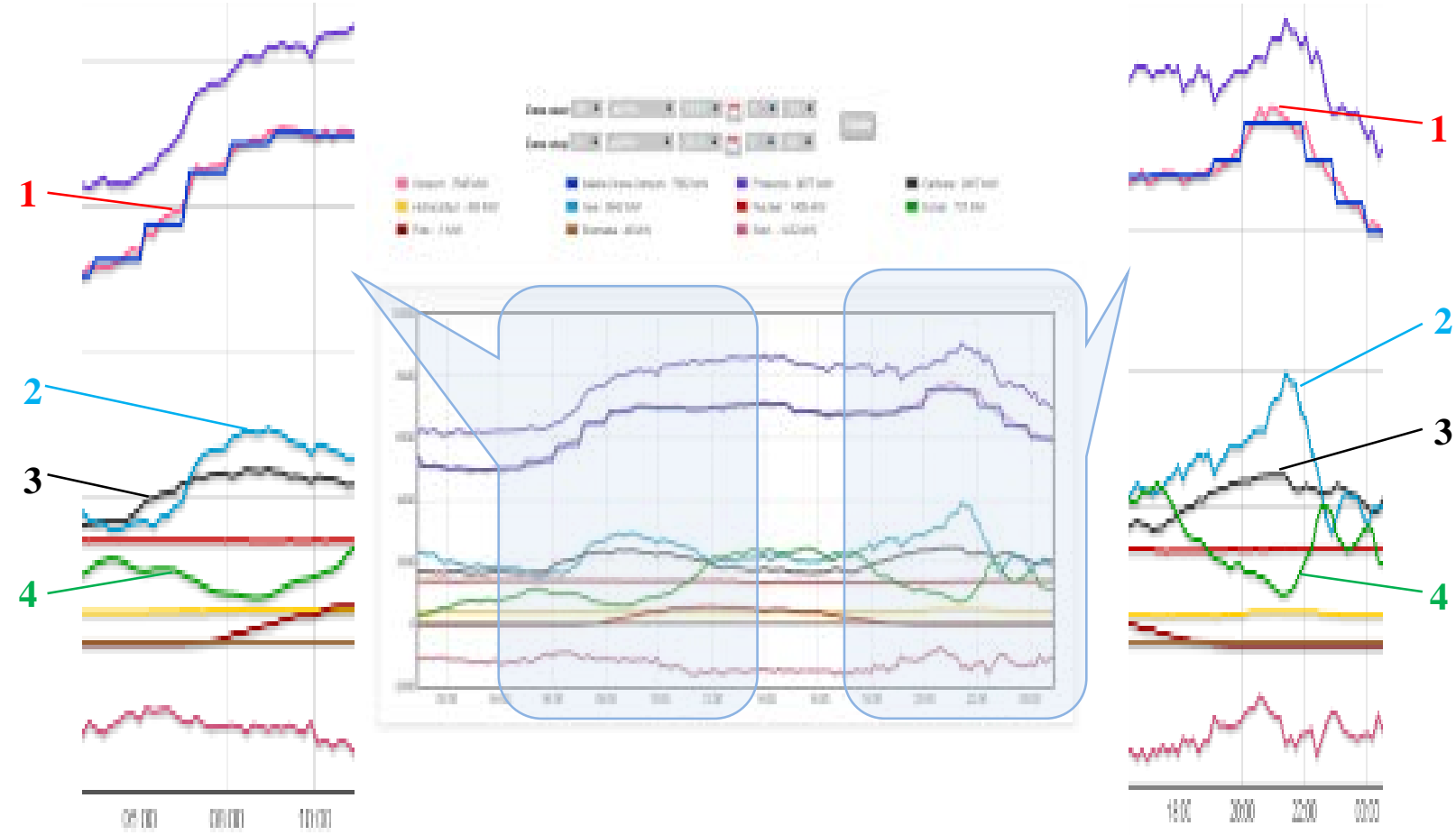

Fig.1. The evolution of the electricity produced from coal, hydroelectric power, wind energy, photovoltaic energy. [6] 
Instant consumption Graph 1-red, must be supported with thermoelectric energy Graph 3-black, hydroelectric energy Graph 2-blue and wind energy Graph 4-green. In that period there was no drought, and thus makes energy produced by hydroelectric plants to compensate peak consumption load, but not total, and clearly see significant compensation performed by coal power plants. To this, add that wind energy Graph 4-green, which is a priority in the system, significantly decreased. This supports the idea that the dynamics of the operation of coal power plants should be increased to meet the new requirements of operation.

We can say simplistic as " a coal power plant works as the wind blows". This high new dynamic for coal power plants, leading to low efficiency operation, to increase the price per MW, and the appearance of a phenomenon of "stress" on the installation that generates wear and costs.

At the present, for the thermal power plant, automatic control systems carry only monocotur control loops with control laws PID (Proportional Integrator derivatives), to which are added feed-forward corrections. This approach, however classic, is made, because of the high complexity of process controled, to which are added experimental design possibilities of a law PID. Process modeling is difficult to do, and in these circumstances the design of evolve control algorithms is difficult. However, due to higher dynamics of operation are "impose" redesign the classics control algorithms, and bringing them into the evolve control algorithms.

However, the complex process, which is a thermal power plant can be analyzed in depth by the current system of automation that shows on-line over 5000 measurement points, and the history of evolution of the process over a great period of time. This is an idea that will be studied and I think a great results will appear.

\section{The impact of increased system stability}

The idea of stability for a thermal power plant is approached in the context of declining number of accidental shut down. The simulation is made for accidental shutdowns are mainly because of the instability the complex system represented by thermal power group and not other factors, such as equipment failure components.

To begin we make a specification: Romanian money are called "lei”, and they value is $1 \mathrm{EU}=4.5$ lei

In these types of accidental shut down, we take into account some additional costs only when the system restart hot, meaning that there is nothing defective physical in the plant and try almost immediately restart thermal power group.

We suppose these costs of restart:

$X=100.000,00$ lei

Under these costs will be detailed following components:

- Consumption of coal in thermal power necessary to bring the group in operating state.

- Electric energy consumption needed to restart that is taken from the energy system during restart, that thermal power plant becomes a consumer of electricity fairly important.

We suppose and losses due to operational failure during shutdown, when in fact, the group had planned a specific thermo energy production.

We suppose an average load per 1 hour for the thermal power group:

$P=250 M W h$

We suppose the time for hot restart:

$$
t_{r}=3 \mathrm{~h}
$$

We suppose the price per $M W h$ is variable depending on the schedule within 24 hours in the area:

$$
\text { [10 lei / MWh....350 lei / MWh] }
$$

If the thermal energy plant is unable to deliver the thermal power energy, will be forced to buy from the system and consider the maximum penalty price:

$$
\text { Price }_{\mathrm{pen}}=350 \text { lei } / \mathrm{MWh}
$$

In these circumstances, we assume the average selling price within 24 hours as:

$$
\text { Price }_{\mathrm{m}_{\_} \text {sale }}=200 \text { lei } / \text { MWh }
$$

Suppose that the price of production is:

$$
\text { Price }_{\mathrm{m} \_ \text {production }}=120 \text { lei / MWh }
$$


Thus, if there was an accidental shutdown, the selling price would have been in the 3 hours, while it lasted restart:

$$
\text { Price }_{\text {sale }}=P \bullet t_{r} \bullet \text { Price }_{\mathrm{m} \_ \text {sale }}=(250 M W h) \bullet(3 h) \bullet(200 \text { lei } / M W h)=150.000,00 \text { lei }
$$

Production costs within three hours:

$$
\text { Price }_{\text {production }}=P \bullet t_{r} \bullet \text { Price }_{\mathrm{m}_{\text {_production }}}=(250 \mathrm{MWh}) \bullet(3 \mathrm{~h}) \bullet(120 \text { lei } / \mathrm{MWh})=90.000,00 \text { lei }
$$

The profit within three hours:

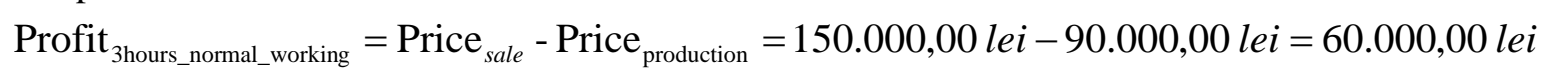

In case of a accidental shut down, we assume that the penalties will be:

$$
\text { Price }_{\text {penalty }}=P \bullet t_{r} \bullet \text { Price }_{\text {pen }}=(250 M W h) \bullet(3 h) \bullet(350 \text { lei } / M W h)=262.500,00 \text { lei }
$$

The losses due to accidental shut down are:

$$
\text { Profit }_{\text {3hours_accidental_shut_down }}=\text { Price }_{\text {sale }}-\text { Price }_{\text {penalty }}=150.000,00 \text { lei }-262.500,00 \text { lei }=-112.500,00 \text { lei }
$$

Total losses will be reflected by the fact that the energy group will not produce the thermal power in 3 hours respectively profit:

$$
\text { Profit }_{\text {3hours_normal_working }}=60.000,00 \text { lei }
$$

and also will have additional losses

$$
\text { Profit } \text { 3hour__accidental_shut_down }_{1}=-112.500,00 \text { lei }
$$

Thus the total losses for accidental shut down are:

$$
\begin{aligned}
& Y=\mid \text { Profit }_{\text {3hour__normal_working }}|+| \text { Profit }_{\text {3hour__accidental_shut_down }} \mid= \\
& =60.000,00 \text { lei }+112.500,00 \text { lei }=172.500,00 \text { lei }
\end{aligned}
$$

Thus, we can consider total costs for hot restart + loss due to failure of the thermal power of the group after accidental shut down:

$$
A=X+Y=100.000,00 \text { lei }+172.500,00 \text { lei }=272.500,00 \text { lei }
$$

For financial projection, we consider five year accidental shut down for one group, ie expenses (B) will be:

$$
B=5 \bullet A
$$

By improving control algorithms, we assume that the target of the group the thermal power stability will act to decrease the number of accidental shut down from 5 to 3 , that new spending (B ') will be:

$$
B^{\prime}=3 \bullet A
$$

In this situation it will save the money:

$$
S=B-B^{\prime}=5 \bullet 272.500,00 \text { lei }-3 \bullet 272.500,00 \text { lei }=545.000,00 \text { lei } \approx 122.000,00 \mathrm{EU}
$$

Analysis of impact category, stops at the the thermal power to one energy group, but when considered as a thermal power plant has more generating units, the results are even more spectacular.

\section{The impact of increasing the efficiency of the system}

This involves increasing the capacity of performance indicators to track reference power required by the national dispatcher. Reference electric power $\mathrm{P}_{\text {ref_hourly_power }}$ is the hourly power value that is required by the National Energy System Dispatcher for Thermal Power Plant.

Under this approach, we consider the secondary control system services, after an initial qualification at the level of a power plant are in the band $30 \mathrm{MW}$, ie in the area zones $\pm 15 \mathrm{MWh}$ around power reference $P_{\text {ref_hourly_power }}$, as in Fig.2.

The current qualification involves modifying the power produced with a slope of loading or unloading the thermal power group with:

$$
\text { slope }{ }_{2 M W}=2 M W / \mathrm{min} \text {. }
$$

Consider the time interval, called time variation of maximum secondary control reserve $t_{r}=15 \mathrm{~min}$ and thus obtain a current power band:

$$
B_{p_{-} 30}=t_{r} \bullet\left(\text { slope }_{2 M W}\right)=(15 \mathrm{~min}) \bullet(2 M W / \mathrm{min})=30 M W
$$


Increased efficiency performance control implies that mainly grow and increase speed of loading / unloading of the group amounted to: slope $_{3 M \mathrm{~W}}=3 \mathrm{MW} / \mathrm{min}$.

For the same time interval, noted above the modification time of maximum secondary regulation reserve $t_{r}=15 \mathrm{~min}$, obtain a new power band of:

$$
B_{p_{-} 40}=t_{r} \bullet\left(\text { slope }_{3 M W}\right)=(15 \mathrm{~min}) \bullet(3 M W / \mathrm{min})=45 M W .
$$

May be performed preliminary tests to qualify as a provider of a secondary regulation with control band $B_{p_{-} 40}=40 M W$ (5MW difference is additional consumption can be considered for a higher bandwidth).

Consider a operating time for an energy group in the secondary regulation $t_{\text {operating_secondary_reg }}=5000 \mathrm{~h}$ of the $8750 \mathrm{~h}$ of a one year with increased band $B_{p_{-} 40}=40 \mathrm{MW}$.

We also consider an additional cost for secondary regulation Price secondary_reg $=63$ lei / $M W$.

Results for the secondary regulation:

$$
\begin{aligned}
& \text { Profit }_{\text {Slope_30MW }}=\left(t_{\text {operating_secondary_reg }}\right) \bullet\left(B_{p_{-} 30}\right) \bullet\left(\text { Price }_{\text {secondary_reg }}\right)= \\
& =(5000 \mathrm{~h}) \bullet(30 \mathrm{MW}) \bullet(63 \text { lei } / \mathrm{MW}) \Rightarrow \text { Profit }_{\text {Slope_30MW }}=9.450 .000,00 \text { lei } / \text { year } \\
& \text { Profit }_{\text {Slope_40MW }}=\left(t_{\text {operating_secondary_reg }}\right) \bullet\left(B_{p_{-} 40}\right) \bullet\left(\text { Price }_{\text {secondary_reg }}\right)= \\
& =(5000 \mathrm{~h}) \bullet(40 \mathrm{MW}) \bullet(63 \text { lei } / \mathrm{MW}) \Rightarrow \text { Profit }_{\text {Slope_40MW }}=12.600 .000,00 \text { lei } / \text { year }
\end{aligned}
$$

Profit $_{\text {total_year }}=$ Profit $_{\text {Slope_40Mw }}-$ Profit $_{\text {Slope_30Mw }}=12.600 .000,00$ lei / year $-9.450 .000,00$ lei / year

$\Rightarrow$ Profit $_{\text {total_year }}=3.150 .000,00$ lei / year $\approx 700.000,00$ EU / year

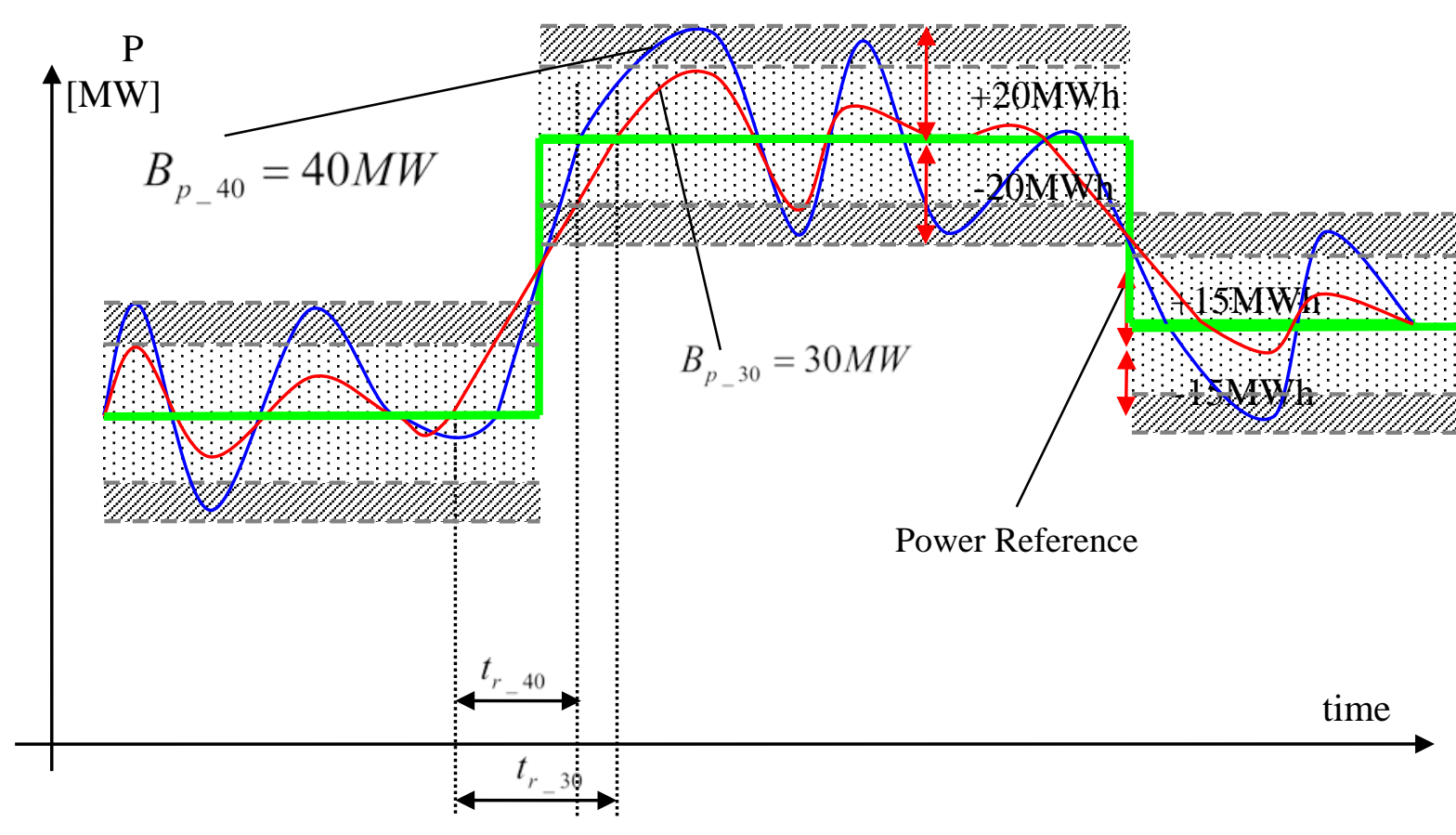

Fig.1. Increased efficiency and performance for increase speed of loading / unloading of the group for slope ${ }_{3 \mathrm{MW}}=3 \mathrm{MW} / \mathrm{min}$.

From relationships (1) and (2), an additional profit/year result due only improve control algorithms :

$\Rightarrow$ Profit $_{\text {TOTAL }}=$ Profit $_{\text {total_year }}+S \approx 700.000,00$ EU / year $+122.000,00 E U \approx 722.000,00$ EU / year

4. The way to improve the control solution at a energy group level to increase the stability and efficiency of coal power plant 
In automatic control of processes were developed more and more complex control algorithms, algorithms that need a lot of information about the process, and also processing this information is very complex and must be done in real time. The main idea, described in detail below, is "reverse engineering" type, that is the path of reverse design of a control system [1], [2]. In this sense we know, by direct measurement, the response of a control loop (actually the process), and knowing the base control law that already works effectively, we develop a method to obtain the mathematical model of the process.

Due to the current automation level, existing at a energy group at coal power plant, it occurs following possibility: in the block diagram of a control loop (Fig.3.) that already operate in the automation system, we can apply a design reasoning backwards (reverse engineering), knowing the block $R$ - the control law that works in real time, knowing the dynamics $H_{0}$ - the response in real-time in closed circuit, the process $P$ will be estimated.

The global function for control loop (feedback) is: $\quad H_{0}=\frac{R \cdot P}{1+R \cdot P}$

In (3), given that $H_{0}$ - is the dynamic what characterizes the current real operation of the process in real time and can be obtained without problems in the process of analyzing real responses to different operating modes, we can consider it as known. In the previous relation (3) it is known the mathematical function $R$ that is implemented and already works the control loop

Having known $H_{0}$ and $R$, from relation (3) it will result the principle relation that will be the basis for estimation and identification processes [3], [4], [5]:

$\Rightarrow P=\frac{H_{0}}{R \cdot\left(1-H_{0}\right)} \Rightarrow P=f\left(H_{0}, R\right)$

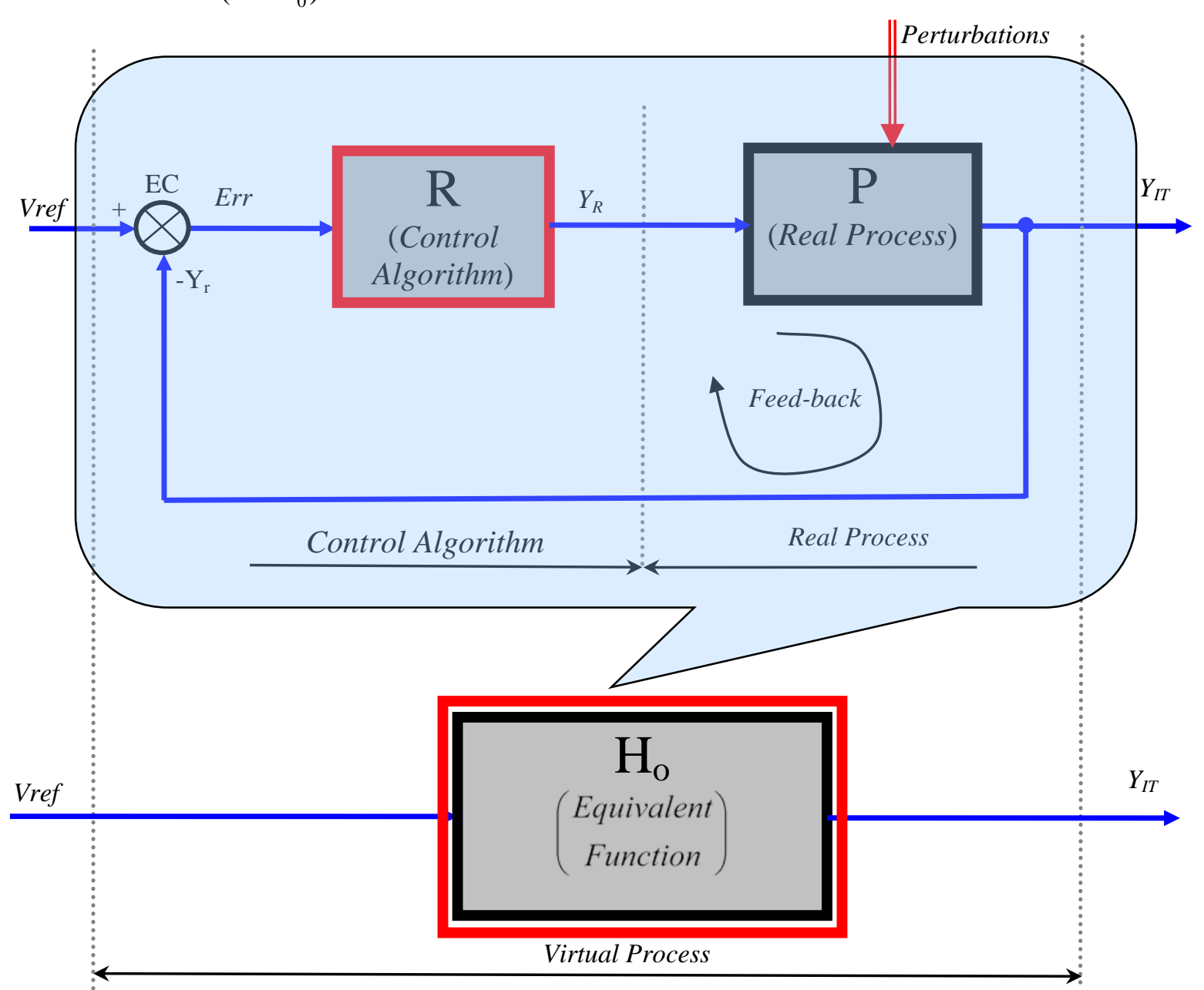

Fig.2. The control loop for energy group

The principled relation (4) suggests that the mathematical model of the process $P$ can be obtained by following the steps reversed, namely knowing the control algorithm $R$, and measuring various responses of real control loop that will generate the knowledge of the dynamic $H_{0}$. The previous 
idea is developed for as many subprocesses what are already working and managed by the existing automation system, in the great complexity process represented by an energy group.

Thus, "knowing" the process, by identifying / modelling, it will be proposed to redesign some of the existing control structures, a solution to design a distributed and hierarchical control structure that take into account the interactions / inter-influences between different real physical quantities or control loops.

\section{CONCLUSIONS}

At the moment, at least 100 main control loops are implemented in an energy group and they are „relative” independently functioning, altough they are a part of the same process and they are strongly interconnected. The term „relative” refers to the fact the interconnection between the control loops are managed by feed-forward correction. When putting into service the group, the designing of these corrections was based on experimental approaching. During the functioning, these control loops are influencing each other (they begin to make small „errors” inducing resonance) leading in time to instability. In this situation the energy group should be turned off. For example, the temperature of the live steam is influenced by the pressure of the live steam, which means that the 2 control loops, one for temperature and one for pressure, will inevitably influence each other dinamically.

By identifying / modelling the processes of the energy group we will be able to redesign/improve the parameters of the control algorithm already implemented, so a higher stability will be obtained in time [1], [2] (for example, the less frequent releases of the energy group will lead to the elimination of the costs generated by the restarts, also the elimination of the losses resulted from not accomplishing the planned production).

Although existing automation level is quite advanced, the problem still remains, still very difficult to resolve, to design the control algorithm that leading to "the best decision" for process command and control. Solving this problem (although the solution is not unique) underlies the idea of increasing the productivity and performance will determine the level of results that will be obtained.

\section{Acknowledgment:}

This work was supported by the strategic grant POSDRU/159/1.5/S/133255, Project ID 133255 (2014), co-financed by the European Social Fund within the Sectorial Operational Program Human Resources Development 2007-2013.

\section{References}

1. Marian Popescu, Ilie Borcoși, "Increasing productivity at the level of the power plant by optimizing the distributed systems and hierarchical systems", Annals of the University Constantin Brancusi, Series Engeneering, ISSN 1842-4856. No.3/2013, pp. 241-244, (2013)

2. Ion Marian Popescu, "Necessity Implementation of advanced control algorithms in the complex processes in the energy industry", Annals of the University of Craiova, Series: Automation, Computer, Electronics and Mechatronics, ISSN 1841-0626, Vol.11 (38), issue 1, (2014).

3. Mathieu Pouliquen, Olivier Gehan, Eric Pigeon "An indirect closed loop subspace Identification method”, 49th IEEE Conference on Decision and Control, DOI: 10.1109/CDC.2010.5717786, (2010)

4. Alessandro Chiuso, Giorgio Picci, "Consistency analysis of some closed-loop subspace identification methods”, Automatica,Volume 41, Issue 3, March 2005, Pages 377391, doi:10.1016/j.automatica.2004.10.015

5. Rohan Mandloi, Pritesh Shah, "Methods for closed loop system identification in industry", Journal of Chemical and Pharmaceutical Research, pp. 892-896, ISSN : 0975-7384 ( 2015)

6. www.transelectrica.ro 